\title{
Tips for roving reference
}

\author{
How to best serve library users
}

\author{
by Martin Courtois and Maira Liriano
}

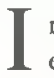
n the late 1980s and early 1990s, reference departments began to experiment with roving as a means of providing assistance to users at increasing numbers of OPAC terminals and CD-ROM stations. Several articles reported on these experiments and introduced the idea of roving as an effective means of serving clientele who were not reached through the traditional reference desk. $^{1}$

The basic idea behind roving is that the library employee circulates within the reference area to offer assistance to users. A roving librarian approaches the user, rather than waiting for the user to come to the reference desk. The growth of Web-based and full-text sources has increased the need for patrons to use a computer when doing library research. This situation creates even more demand for point-of-use assistance to help users through a challenging and confusing array of sources. Remote access is welcomed by many users, but within the library there is a need to provide a helpful, human presence in this increasingly electronic environment.

Recent discussions at ALA and on LIBREF$\mathrm{L}$ inclicate that increasing numbers of libraries are offering roving reference. ${ }^{2}$ Libraries report overwhelmingly positive response from users, but also describe a few problem areas: librarians who are unwilling to rove, frustration with the number of basic equipment questions (jammed printers, frozen PCs, etc.), and clifficulty in establishing roving as a consistent and quality service.

Drawn from these discussions and our experience at George Washington University (GWU), we offer the following suggestions for providing roving reference. In the first section, we describe techniques that rovers can employ when working with users, followed by ideas that departments can use to initiate or expand roving services.

\section{Roving techniques}

- Wear a nametag or badge. If you're not behind the reference desk, users may not recognize you as part of the reference staff. Some form of identification is a quick and easy way to establish credibility with users. Particularly in busy reference areas, it's difficult to distinguish reference staff from other users. Badges with school colors, the library logo, and labels such as "Librarian" or "Reference Staff" will help users to identify you as the rover and encourage them to ask for assistance.

- Be mobile. A key ingredient of roving is mobility. Don't stay too long with any one user. Get the user started on the initial steps of their search, then move on to other users. Promise to check back with the user or en-

\section{About the authors}

Martin Courtois is science collection development librarian and Web development group leader at George Washington University, e-mail: courtois@gwu.edu; Maira Liriano is reference and information services group leader at George Washington University, e-mail:Iriano@gwu.edu 
courage them to let you know when they're ready for the next step. If you're sitting down at the workstation and the user is looking over your shoulder, you've lost your effectiveness as a rover.

- Follow up with users. After you help a user start a search, check on his or her progress. This is an effective reference desk technique that is easy to do when roving. In large or busy reference areas it may be difficult to remember everyone you want to revisit; carry a small notepad and jot down reminders.

- Address the user before addressing their screen. Users are unlikely to confide in you and discuss their needs if they perceive you as "policing" the area. You may indeed need to watch for inappropriate use of stations, but let that task be secondary to offering assistance. It's likely that you will notice screens that are displaying ineffective search statements, immense result sets, or error messages. These situations present good lead-ins to approaching the user, but be discreet.

- Think in terms of welcoming behaviors. How do you like to be approached by sales people in a retail store? When you enter a restaurant, how do you like to be treated? These establishments focus on generating repeat customers, and we need to do the same. Focus on putting users at ease and making them feel welcome

- Address each user. We have seen several techniques for roving. In passive roving, the rover doesn't make the first step in approaching users, but merely walks around the reference area and waits to be summoned for assistance. In the broadcast method, the rover announces an offer of assistance to a group of users, e.g., "Anyone here have any questions?" We feel the individual approach is the most effective. Approach each user and offer assistance with lines such as, "Are you finding what you need?" "Can I help you with anything?" or "How is your search going?"

- Be prepared for indifference. After you've made your offer, don't expect or force a response. Some users will respond instantly with a description of their problem. Others may decline with a "No, thank you," and some may ignore you. Don't press the issue, and don't make the user uncomfortable. Let the user decide how and when the interaction will proceed. If the user doesn't need your help right now, he or she may have a question in a few minutes and will know that you are available to help.

\section{Implementing roving}

- Prepare staff to rove. Not all staff will feel comfortable with roving right from the start Offer encouragement, but be patient. Make roving a topic for department meetings and ask experienced/enthusiastic rovers to share their techniques and positive experiences. Rovers need to project confidence and a helpful attitude. Forcing librarians who aren't prepared to rove will not benefit users.

- Schedule times for roving. If your staffing level permits, schedule times when a particular staff member(s) is the designated rover. Ideally, this would be during busiest times and will give staff scheduled at the reference desk more time to work with users on indepth questions. Scheduling staff to rove will get them out on the floor and accustomed to the idea of roving. Once they've tried it and experienced positive feedback, they will be more likely to make roving part of their routine, even during unscheduled times.

- Use your best people as rovers. A good rover needs to project confidence, a helpful attitude, and a thorough knowledge of resources to win the trust of the user and elicit questions. Is a student assistant with a few hours' training the best person for this job? Rather, we feel it's more effective to use librarians or experienced support staff as "front-line" rovers and employ students or other assistants to handle referrals from rovers.

- Use assistants for back-up or tech support. Student assistants can be used effectively for technical support. It's more realistic to provide training for students to handle routine printer, computer, and network prol)lems than to train them to be reference librarians. Having assistants available to handle basic technical questions will free rovers to concentrate on helping users with their search questions and not get bogged down in fixing printer jams and rebooting computers.

- Create an atmosphere of active learning. Some librarians are concerned that roving violates users' privacy. While it's important to respect this, it's also important to (continued on page 315) 


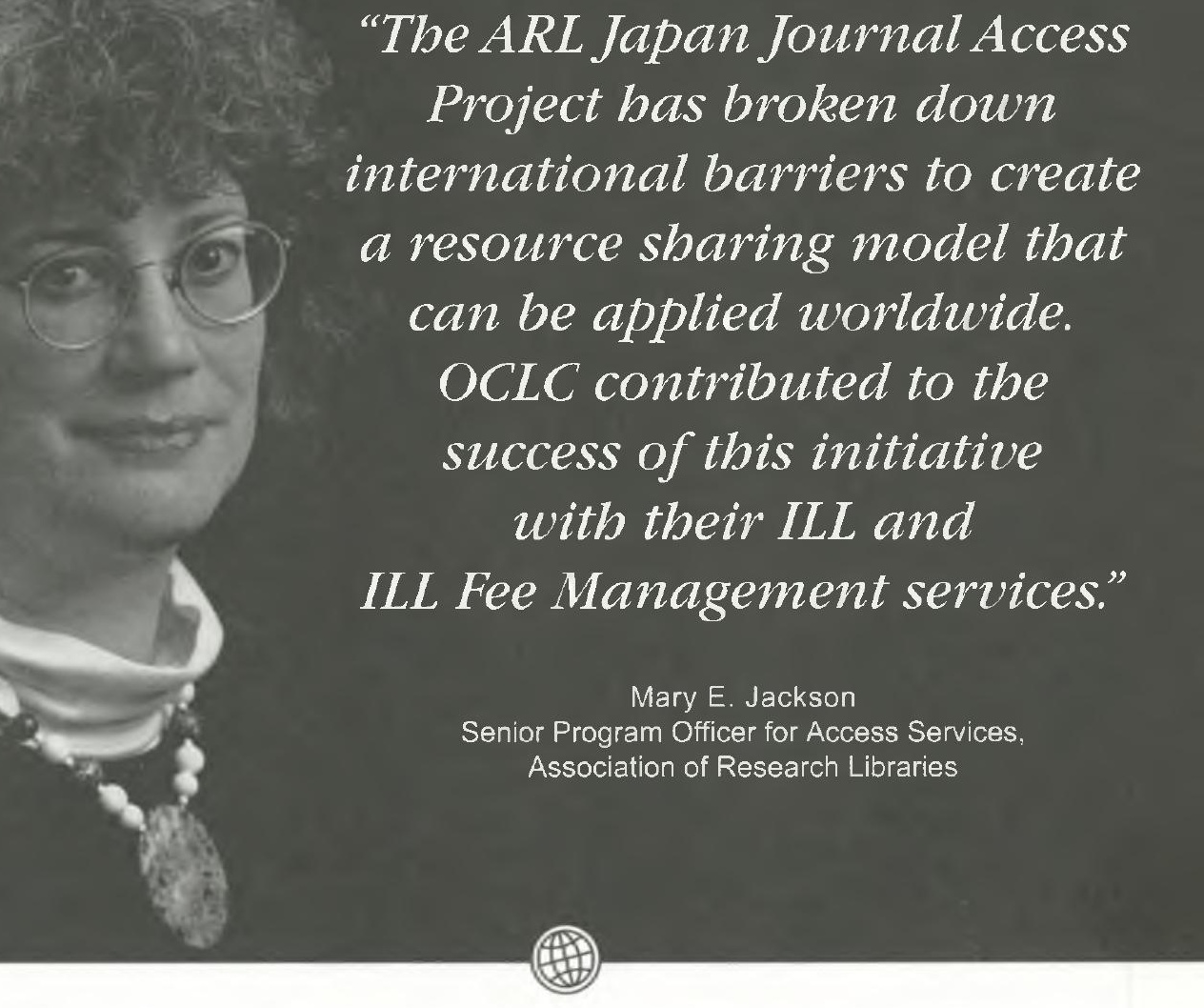

The Japan Journal Access Project is a collaborative effort involving Waseda University (one of Japan's leading research institutions), 18 research libraries in Canada and the U.S., the Association of Research Libraries and OCLC. This project gives students and scholars easy access to Waseda University's extensive collection of materials via the OCLC global resourcesharing network.

Most notably, the ILL Fee Management service eliminates difficulties associated with currency exchange by providing a single invoice in local funds.

For over 25 years, libraries have been working together through OCLC to further access to information and reduce library costs. OCLC member libraries cooperatively created WorldCat ${ }^{\circledast}$ (the OCLC Online Union Catalog), which is now the most consulted database in higher education.

At OCLC we continue to develop new ways to provide innovative and affordable library services for our membership. For example, we are working with 200 OCLC member libraries on an international research initiative that is using automated cataloging tools and library cooperation to create a research-quality database of Web resources.

For information about what you can do now with OCLC services, please contact us at:

purl.oclc.org/oclc/crin 1-800-848-5878, ext. 6251 


\section{ANY JOURNAL}

ANY FORMAT

\section{ANY TIME}

440 Crumery Was Sulo A

Exton, PA 18541-2851

Phone: bx0-4ti-9se?

Fax: $800-680 \times 9850$

http:/iwmenswesblokwetcon
$\mathrm{POB} 2 x+207$

Bodknood/NJ 0.012

Prenc 8x 486.3786

Fux B56.232-7334
PO Bex a0 Hythe Brdgs Street

Cotord OXI 2EU, UK

Ficre o1t 441985 79erng

Fav 011 \&4 1586282539 
also have good communication and structure so that all participants understand their responsibilities to themselves and the group. The structure is dynamic but the processes for learning can be articulated within that structure. Comfort with risk-taking on the part of students and instructors is one important goal.

The discussion ended by sharing individual highlights. Memorable aspects of the discussion for participants included remembering to embrace the messier aspects of learning, seeking to balance cognitive with affective learning, searching for collaboration opportunities with new partners, and stressing the primacy of outcomes while we experiment and take risks.

Learning communities have a lot to teach us as we continue to develop library instruction programs for our diverse student populations. The opportunities provide for rethinking how we approach our patrons and our teaching. Dynamic learning communities offer attributes that can be adapted into libraries or programs of any size.-Jennifer Evans, University of Washington Libraries, jrevans@ u. uashington.edu

\section{(Tips . . continued from page 290)}

establish the reference area as a place for active learning where the focus is on dialogue and interaction. Research done by Swope and Katzer more than 25 years ago revealed that $65 \%$ of users who have a question in mind said they would not ask a librarian for help. ${ }^{3}$ Roving offers a way to draw out those unasked questions.

- Refer questions from the reference desk to the rover. Even with an active roving service, it's important to maintain a presence at the reference desk. Librarians scheduled at the desk should try to refer patrons who need to use a public workstation to the rover. This will allow desk librarians the flexibility to work with users who may have more complex questions and steer the user to the rover, who will be in a better position to offer follow-up assistance.

- Keep statistics. Many reference clepartments report declining numbers of reference questions. This decrease may be because fewer transactions take place solely at the desk, but more users are helped at public workstations. This may be difficult to do, but look for ways for rovers to keep accurate count of the number of questions they answer. Your statistics should jump dramatically!

\section{A final recommendation}

While it's helpful to share our experiences and ideas, it may be more beneficial to move toward a codification of specific behaviors for roving.

Considerable attention has been devoted to the behavior and performance of librarians working at reference desks, as seen in guidelines prepared by ALA's Reference and User Services Association. ${ }^{4}$ On one level, rov- ing is an extension of traditional reference; working at the reference desk and roving require many of the same skills and behaviors.

Roving, however, brings to play interpersonal dynamics that can be quite different from those encountered in a reference desk setting. Further examination and discussion will help to identify standards that will increase the overall quality and consistency of roving reference.

\section{Notes}

1. Adeane Bregman and Barbara Mento, "Reference Roving at Boston College: Point of Use Assistance to Electronic Resource Users Reduces Stress," College and Research Libraries Neus 53 (November 1992): 634-35; Eileen H. Kramer, "Why Roving Reference: A Case Study in a Small Academic Library," Reference Services Review 24 (Fall 1996): 67-80; Jennifer Mendelsohn, "Human Help at OPAC Terminals is User Friendly: A Preliminary Study," RQ 34 (Winter 1994): 173-90.

2. "Roving Reference: A Human Presence for the Information Age," RUSA/MOUSS Performance Issues for Reference and Information Service Librarians Discussion Group, ALA Annual Conference, New Orleans, June 26, 1999; Martin Courtois and Maira Liriano, "Summary on Reference Roving," posted to LIBREF-L, May 18, 1999. http:// listserv.kent.edu/archives/libref-l.html [9/29/ 99].

3. Mary Jane Swope and Jeffrey Katzer, "Why Don't They Ask Questions?," $R Q 12$ (Winter 1972): 161-66.

4. "Guidelines for Behavioral Performance of Reference and Information Services Professionals," January 1996. http://www.ala.org/ rusa/behavior.html [9/29/99]. 